\title{
EMMPRIN/CD147 up-regulates urokinase-type plasminogen activator: implications in oral tumor progression
}

\author{
Géraldine Lescaille1, Suzanne Menashi², Bénédicte Cavelier-Balloy ${ }^{3}$, Farah Khayati', Cathy Quemener ${ }^{1}$, \\ Marie Pierre Podgorniak ${ }^{4}$, Benyoussef Naïmi ${ }^{5}$, Fabien Calvo ${ }^{1,6}$, Céleste Lebbe ${ }^{6,7}$ and Samia Mourah ${ }^{1,4,6,8^{*}}$
}

\begin{abstract}
Backgrounds: An elevated level of EMMPRIN in cancer tissues have been correlated with tumor invasion in numerous cancers including oral cavity and larynx. Although EMMPRIN's effect has been generally attributed to its MMP inducing activity, we have previously demonstrated in breast cancer model that EMMPRIN can also enhance invasion by upregulating UPA. In this study, the role of EMMPRIN in regulating UPA and invasion was investigated in oral squamous cell carcinoma (OSCC) progression.
\end{abstract}

Methods: Precancerous and invasive oral tumoral tissues were used as well as the corresponding cell lines, DOK and SCC-9 respectively. The paracrine regulation of UPA by EMMPRIN was investigated by treating culture cells with EMMPRIN-enriched membrane vesicles. UPA expression was analyzed by qPCR and immunostaining and the consequence on the invasion capacity was studied using modified Boyden chamber assay, in the presence or absence of EMMPRIN blocking antibody, the UPA inhibitor amiloride or the MMP inhibitor marimastat.

Results: OSCC tumors were shown to express more EMMPRIN and UPA compared to dysplastic lesions. The corresponding cell models, SCC-9 and DOK cells, displayed similar expression pattern. In both cell types EMMPRIN upregulated the expression of UPA as well as that of MMP-2 and MMP-9. EMMPRIN treatment led to a significant increase in cell invasion both in the invasive SCC-9 and in the less invasive dysplastic DOK cells, in an MMP and uPA dependent manner.

Conclusions: Our results suggest that the upregulation of UPA contributes to EMMPRIN's effect in promoting oral tumor invasion.

Keywords: EMMPRIN/CD147, uPA, Oral squamous cell carcinoma, Invasion, Progression

\section{Background}

Oral squamous cancer cell carcinoma (OSCC) ranks among the top ten most frequently cancers, and 500 000 people per year are world widely diagnosed [1]. OSCC is highly invasive with bad prognosis; despite the recent advances in cancer therapy, the 5 -year survival rate of patients has remained at $<50 \%$ [2]. Little is known about of the molecular events that govern OSCC initiation, progression and metastasis. Development of OSCC is a complex and multistep process, with transformation from oral premalignant dysplastic lesion to

\footnotetext{
* Correspondence: samia.mourah@sls.aphp.fr

${ }^{1}$ Inserm, UMR-S 940, Paris F-75010, France

Full list of author information is available at the end of the article
}

OSCC. Progression is generally known to involve the intervention of proteinases [3-5]. Extracellular matrix metalloproteinase inducer (EMMPRIN/CD147), a membrane glycoprotein greatly enriched on the surface of tumor cells, is mainly known for its ability to increase the synthesis of MMPs in tumor cells and in the neighbouring stromal cells, such as fibroblasts and endothelial cells [6-10]. EMMPRIN has been implicated in tumor invasion and its elevated levels in cancer tissues have been correlated with tumor progression in numerous malignant tumor models including tumors of the oral cavity and larynx $[11,12]$.

In addition to increasing invasion through proteinase induction, EMMPRIN induces several other malignant 
properties associated with cancer. These include, amongst others, the stimulation of cell survival signaling, including Akt, Erk and FAK, through the increased production of the pericellular polysaccharide hyaluronan [13]. Also, EMMPRIN can promote angiogenesis by the upregulation of VEGF expression as well as its main receptor VEGFR-2 in both tumor cells and endothelial cells [14-16]. This effect on VEGF and VEGFR-2 was shown to be mediated by HIF-2 $\alpha$ [17].

The role of EMMPRIN in tumor growth and invasion was illustrated by the accelerated growth and increased invasiveness of EMMPRIN-overexpressing human breast cancer cells $[18,19]$. The increased tumor size in the EMMPRIN overexpressing cells was associated with an increase, in the tumors, of not only MMP-2 and MMP$9[18,19]$, but also of urokinase type plasminogen activator (UPA) levels [18]. Indeed, we have previously reported that EMMPRIN is able to upregulate the expression of the plasminogen activation system, including $\mathrm{uPA}$, in mammary tumor cells, further increasing its proteolytic and invasion potential [18].

Microarray analyses of primary oral tumors have identified UPA and its receptor (UPAR) as key genes associated with human OSCC progression [18,20,21]. Human OSCC tumors with high levels of UPA and UPAR are more invasive, exhibit enhanced lymph node metastasis and more frequent tumor relapse [22].

Increased expression of EMMPRIN in oral squamous cell carcinoma has been shown to correlate with lymphatic metastasis and tumor progression [23]. EMMPRIN overexpression has been previously reported to occur at a very early stage of oral carcinogenesis and to play a contributing role in OSCC tumorogenesis [24]. Its role in facilitating tumor cell motility was attributed to its ability to increase MMP production and tenascin$\mathrm{C}$ matrix deposition $[25,26]$. In this study using both invasive and precancerous oral cancer cell models we present evidence suggesting that EMMPRIN promotes oral tumor invasion by inducing uPA expression.

\section{Methods}

\section{Cell culture}

Two cell lines representing two stages of oral tumour progression were used: DOK, a precancerous dysplastic cell line [27] and SCC-9, an oral squamous carcinoma cell line (Rheinwald laboratory). The cells were cultured in DMEM with $10 \%$ fetal bovine serum (FBS) and $2 \mathrm{mML}$-glutamine. Chinese Hamster Ovary (CHO) cells (ATCC, Rockville, $\mathrm{MB}$ ) were cultured in DMEM/F12 (Invitrogen) supplemented with $10 \%$ FBS and $2 \mathrm{mML}$-glutamine.

\section{Membrane preparation}

$\mathrm{CHO}$ cells were stably transfected with a plasmid containing full-lengh EMMPRIN cDNA (CHO-Emp cells) or empty vector (CHO-Mock cells) [18]. CHO-Emp and $\mathrm{CHO}-$ Mock membranes were isolated by differential centrifugation as previously described [18]. The bioactivity of EMMPRIN-containing membranes was verified by its ability to stimulate uPA expression in melanoma cells [18]. The membrane vesicles obtained from the $\mathrm{CHO}-\mathrm{Emp}$ or CHO-Mock cells are referred to as $\mathrm{CHO}-\mathrm{Emp} \mathrm{mb}$ or $\mathrm{CHO} \mathrm{mb}$ respectively throughout.

\section{Small interfering RNA transfection}

EMMPRIN small interfering RNA(siRNA) oligos (Ambion/Applied Biosystems) or scrambled siRNA oligos $(25 \mathrm{nmol} / \mathrm{L})$ were transfected into DOK and SCC-9 cells using the BLOCK-iT transfection kit and Lipofectamine-2000 (Invitrogen), according to the manufacturer's protocol. Cells were then incubated for 24 hours prior to the measurements of uPA mRNA by qRT-PCR and invasion assays.

\section{Western blotting analysis}

Western blot was preformed as previously described [14]. Membranes were immunoblotted with anti-EMMPRIN/CD-147 HIM6 mAb (BD Biosciences) or antiuPAR (R\&D systems) antibodies. Proteins were visualized with ECL reagent (Pierce) and their relative expression was determined by densitometry using ImageJ software program and normalized relative to $\beta$-actin.

\section{Gelatin and casein-plasminogen zymography}

Gelatin or casein-plasminogen zymography was performed as described previously [17]. Serum-free conditioned media were analyzed on 10\% SDS-PAGE gels containing either $1 \mathrm{mg} / \mathrm{mL}$ gelatin for gelatinase activity or $2 \mathrm{mg} / \mathrm{mL}$ casein (Sigma) and $10 \mu \mathrm{g} / \mathrm{mL}$ plasminogen (Calbiochem) for uPA activity.

\section{Real-time quantitative RT-PCR (qRT-PCR)}

Transcript quantification for EMMPRIN, uPA, MMP-2 and MMP-9 was conducted using TaqMan technology and standard curve quantification method. Quantitative PCR were performed using Perfect Master Mix-Probe (AnyGenes, France) on LightCycler system2.0 (Roche, France) according to the manufacturer's techniques. Briefly, cDNAs for EMMPRIN, uPA, MMP-2 and MMP-9 were prepared from total RNA, amplified by RT-PCR, and cloned using TOPO II TA cloning kit (Invitrogen). A standard curve for each transcript was generated using serial dilutions of cloned products ranging from 1 to $10^{9}$ molecules/ $\mu$ l. The copy number of unknown samples was calculated by setting their PCR cycle number to the standard curve. Data were normalized to the TBP (TATA-box binding protein) housekeeping gene transcripts. Primers and probes are 
available under request. All experiments were performed in duplicate.

\section{Invasion and migration assays}

In vitro invasion was assessed using a modified Boyden chamber assay. SCC- 9 and DOK cells $\left(2 \times 10^{4}\right.$ cells/ insert for 24-well plate) were plated onto Matrigelcoated cell culture inserts together with either antiEMMPRIN antibody $(20 \mu \mathrm{g} / \mathrm{mL})$, non-immune IgG, uPA inhibitor amiloride $(20 \mathrm{nmol} / \mathrm{L}$; Sigma) or the MMP inhibitor marimastat $(10 \mu \mathrm{mol} / \mathrm{L}$; British Biotechnology, Oxford, UK). Three hours later CHO-Emp $\mathrm{mb}$ or $\mathrm{CHO} \mathrm{mb}$ were added $(20 \mu \mathrm{g} / \mathrm{ml})$. After 48 hours of incubation, cells on the underside of insert filters were fixed, stained with Diff Quik (Dade Behring) and counted under a bright-field microscope. Migration assay was performed as above, omitting matrigel coating.

\section{Immunofluorescence of cultured cells}

DOK and SCC-9 cells were grown in microscope slide chambers to $50-60 \%$ confluence. CHO-Emp mb or $\mathrm{CHO} \mathrm{mb}$ were then added $(20 \mu \mathrm{g} / \mathrm{ml})$ and 24 hours later, cells were washed in PBS and fixed in $4 \%$ paraformaldehyde for immunofluorescence detection of EMMPRIN or uPA. Slides were probed with mouse antihuman EMMPRIN antibody (HIM6 BD Pharmingen) or with goat anti human uPA antibody (American diagnostica). After incubation with the corresponding secondary antibody (Alexa 488 and 594) the slides were examined with a laser-scanning confocal microscope (Leica Lasertechnik, Heidelberg). Cells were counterstained with DAPI (Sigma).

\section{Analysis of human oral squamous carcinoma and dysplastic lesions}

Tumor samples were collected from 20 patients with oral squamous carcinoma or dysplastic tissues. Tissues of normal oral mucosa were collected from healthy donors attending for tooth extraction. All patients gave their informed consent. Protocols were approved by our institution research ethics committee. Total Formalin-fixed paraffin-embedded (FFPE) tissue sections of 6 normal oral mucosa, 4 intra epithelial neoplasia, 8 micro-invasive OSCC and 8 invasive OSCC, were analysed for EMMPRIN and uPA expression using qRTPCR and immunohistochemistry assays. For immunohistochemistry, FFPE sections were stained with a mouse anti-human EMMPRIN antibody (BD-Pharmingen) and a goat anti human uPA antibody (American diagnostica). Staining was visualized using the streptavidin-biotin-HRP detection method, followed by counterstaining with Mayer's hematoxylin. Three-amino-9-ethyl-carbazole (Sigma-Aldrich, France) was used as the chromogen. For transcript quantification levels, RNA was extracted using TRIzol reagent (Invitrogen). Firststrand cDNA was synthesized using the High-Capacity cDNA Archive Kit (Applied-Biosystems). Transcript levels were measured in each tissue by qPCR using Perfect Master Mix-Probe (AnyGenes, France) on LightCycler 2.0 System (Roche). The expression levels of interesting transcripts were normalized to the housekeeping TATA-box binding protein (TBP) gene transcripts. All experiments were performed in duplicates and Spearman's rank correlation was used to evaluate the association between mRNA levels in oral dysplastic, micro-invasive and invasive tumor tissues.

\section{Statistical analysis}

Data are expressed as mean F SD. Mann-Whitney and Student's t tests were used to compare differences between groups in various experiments.

\section{Results}

EMMPRIN and UPA expression is increased with oral tumor progression

The expression of EMMPRIN and UPA was examined in a tumor series from 20 patients with dysplasctic (4) micro-invasive (8) or invasive lesions (8) and compared with to their expression in normal oral mucosa (6). QRT-PCR analysis has shown that both EMMPRIN and uPA transcripts were proportionally increased with the invasive stage of the tumors (Figure 1A). An average increase of 2.5 fold for EMMPRIN and 11 fold for uPA can be noted between the dysplastic and the invasive stage, while their levels in normal mucosa were the lowest, displaying 5 fold less EMMPRIN and 3 fold less uPA than in the dysplastic lesions.

EMMPRIN and UPA expression was also evaluated by immunohistochemical analysis of tumors obtained from OSCC patients. Figure 1B presents a representative staining pattern showing more intense staining of both EMMPRIN and UPA in burgeoning (micro-invasive) and invasive tumor lesions than dysplastic lesions. Moreover, EMMPRIN and UPA staining was localized in the same areas within the tissue.

\section{EMMPRIN regulates UPA in oral dysplastic DOK and tumoral SCC-9 cell lines}

The association of both EMMPRIN and uPA transcript with oral tumor progression and their colocalization within tumor tissues prompted us to look for a regulation of uPA by EMMPRIN. For that, two cell lines, DOK and SCC-9, representing the dysplastic and the invasive stages respectively were studied. These two cell models present a differential expression of EMMPRIN (Figure 2), with SCC-9 showing higher transcript and protein levels of EMMPRIN compared to DOK cells, 


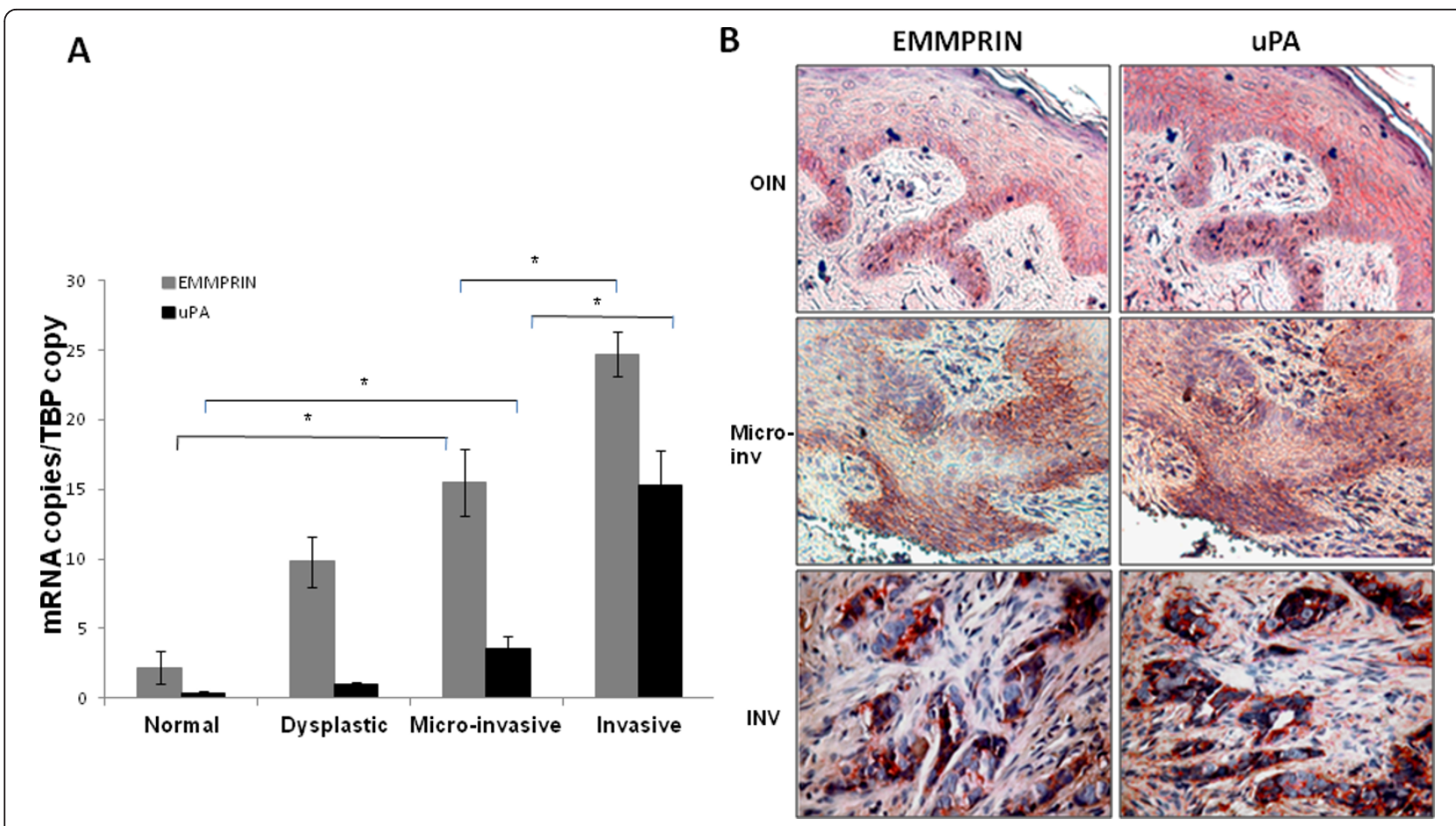

Figure 1 EMMPRIN and uPA expression in human oral dysplastic and squamous carcinoma lesions. A- EMMPRIN and UPA mRNA expression in oral dysplastic and tumor tissues. RNA was extracted from formalin-fixed paraffin-embedded tissue sections of 6 normal oral mucosa (Normal), 4 intra epithelial neoplasia (Dysplastic), 8 micro-invasive OSCC and 8 invasive OSCC, and were analysed for EMMPRIN and UPA expression using qRT-PCR assays. * denotes significant difference with $p<0.05$. B- Immunohistochemical staining of EMMPRIN and uPA in sections of human oral dysplastic, micro-invasive and invasive squamous carcinoma lesions. Tissue sections from patients with oral dysplastic lesions (OIN), micro-invasive lesions (Micro-inv) and invasive oral squamous carcinoma lesions (INV) lesion sections were subjected to singlelabeled immunohistochemistry using mouse anti-human EMMPRIN mAb or goat anti-human uPA Ab and counterstained with HES. EMMPRIN and UPA were colocalized, their staining was heterogeneous with particularly high staining at some regions. Staining was more intense in the tumor sections.

evaluated by quantitative RT-PCR, western blot and Immunofluorescence analyses.

The role of EMMPRIN in the regulation of uPA production in these two cell lines was investigated by treating the cells with exogenously added EMMPRIN. EMMPRIN contained within membrane vesicles was obtained from $\mathrm{CHO}$ cells previously transfected with EMMPRIN full length cDNA. The incubation of DOK and SCC-9 cells with $20 \mu \mathrm{g} / \mathrm{ml}$ of EMMPRIN-containing membranes (designated CHO-Emp) increased uPA protease activity (by $40 \%$ for DOK and $26 \%$ for SCC-9) and RNA levels (5 fold for DOK and SCC- 9) when measured by casein-plasminogen zymography and qRT-PCR respectively, whereas those prepared from mock-transfected $\mathrm{CHO}$ cells $(\mathrm{CHO})$ had no effect (Figure 3A). This was also accompanied by an increase in MMP-2 and MMP-9 measured by qRT-PCR and gelatine zymography. TIMP-1 which was shown not to be an EMMPRIN target [28] was used here as negative control showing no regulation by EMMPRIN in our cell models (Figure 3Ac). The regulation of UPA by EMMPRIN in both cell lines was confirmed by immunofluorescence analysis (Figure 3Ad).

To evaluate the specificity of EMMPRIN's effects, blocking anti-EMMPRIN antibody was added with the EMMPRIN containing membranes and the effect on uPA production was examined by zymography. As shown in Figure 3B, anti-EMMPRIN antibody $(20 \mu \mathrm{g} /$ $\mathrm{mL}$ ), but not IgG control, blocked EMMPRIN's effect on uPA in both DOK and SCC-9 cells. A down-regulation of MMP-2 and -9 activities was also observed (data not shown).

The regulation of uPA by EMMPRIN was also investigated by inhibiting endogenous EMMPRIN expression using RNA interference strategy. EMMPRIN siRNA transfection of DOK and SCC-9 cells showed a significant reduction in the transcript level of uPA (Figure $3 C)$.

Hence, EMMPRIN regulated uPA in both the dysplastic and the invasive tumor cell lines, suggesting a regulatory mechanism involved even at the early tumorogenesis stages 
A

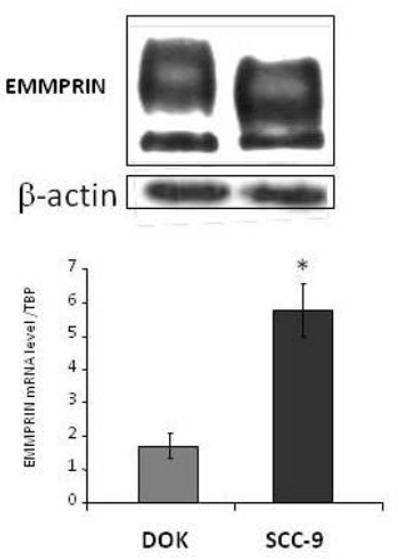

B
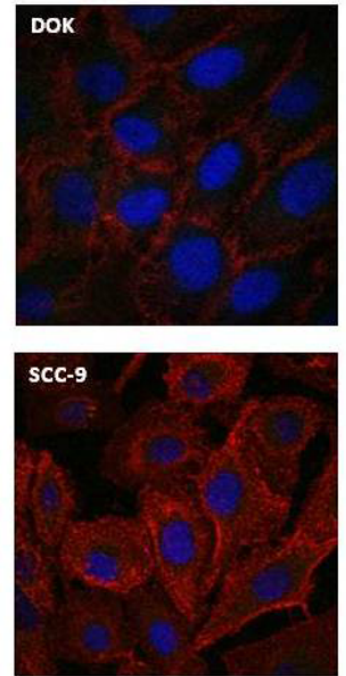

Figure 2 EMMPRIN expression of dysplastic and tumor cell lines. A, EMMPRIN expression was evaluated by western blotting analysis of 10 $\mu \mathrm{g}$ of DOK and SCC-9 cell lysates ( $\beta$-actin was used as loading control). Representative blot is shown. EMMPRIN transcripts in DOK and SCC-9 cells were quantified using quantitative RT-PCR. Columns represent average values from at least three independent experiments carried out in triplicate; bars, SD. * denotes significant difference with $p<0.05$. B, Immunofluorescence staining for EMMPRIN in DOK and SCC-9 cells. Cells were counterstained with DAPI $(\times 400)$. EMMPRIN staining was stronger in the SCC-9 tumor cells compared to the Dysplastic DOK cells.

\section{EMMPRIN promotes in vitro cell invasion in oral tumor progression model}

EMMPRIN has already been implicated in tumor cell invasion [10,29]. This was confirmed in our in vitro experiments using the Matrigel invasion assay, showing an increase in the invasive capacity of both cells, DOK and SCC-9, which was abolished by the presence of 20 $\mu \mathrm{g} / \mathrm{mL}$ EMMPRIN blocking antibody. The rate of invasion of SCC-9, the more aggressive cell type, was greater than that of DOK. In addition, EMMPRIN increased invasion in both cell types by approximately 3 fold, progressing the invasiveness of the dysplastic cells DOK to that of the invasive SCC-9 cells (Figure 4A). It is interesting that EMMPRIN antibody also inhibited the invasion of control cells (treated with CHO-Mock), suggesting that endogenously produced EMMPRIN also contributes to invasion. Cell invasion was also reduced in both cell lines after inhibition of EMMPRIN by siRNA (Figure 4B).

EMMPRIN also had a more significant effect on the Invasion Indices (calculated as percent of invaded cells relative to migrated cells) of SCC-9 compared to DOK. This emphasizes the protease inducing function of EMMPRIN in the invasion process (Figure 4C).

Since EMMPRIN is mostly known to upregulate MMPs, we investigated the relative contribution of the uPA and MMP systems to the invasion capacity of both cell lines. For that, we used $20 \mathrm{nmol} / \mathrm{L}$ amiloride (for $\mathrm{uPA}$ inhibition) and $10 \mu \mathrm{mol} / \mathrm{L}$ marimastat (for a global
MMP inhibition) which were added alone or in combination. As expected, an inhibition of invasion was observed in both cell lines in the presence of either amiloride or marimastat, the inhibition was greater when the inhibitors were used in combination. However, EMMPRIN treatment did not restore invasion in any of these conditions (Figure 4D). These results suggest that EMMPRIN regulates in vitro oral tumor cell invasion through both uPA and MMP activities.

\section{Discussion}

EMMPRIN is widely distributed in many human and mammalian cells, with notably high expression in some of solids cancers including oral squamous cell carcinoma. It's over-expression is associated with malignancy and / or poor prognosis in many tumor types, and several studies suggest that EMMPRIN is an important factor which contributes to oral squamous cell carcinoma growth, invasion, and metastasis [30]. EMMPRIN increased expression was observed at a very early stage of oral carcinogenesis. Indeed, it was shown to increase in dysplastic leukoplakias spreading to more superficial layers, and its expression levels correlated significantly with the degree of dysplasia [24].

The functional importance of EMMPRIN during tumor progression has been related mainly to its ability to promote tumor cell invasion by stimulating MMP and VEGF cytokine production expression [31]. We have previously showed that EMMPRIN can also 
A

(a)

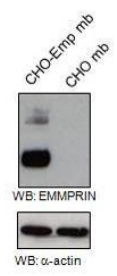

(C)

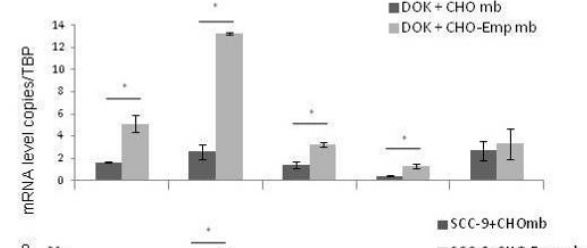

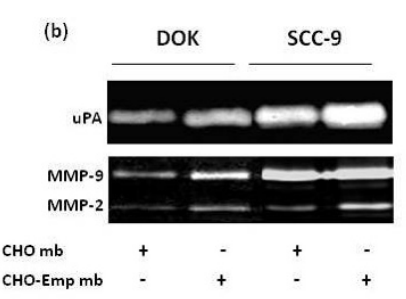

(d)
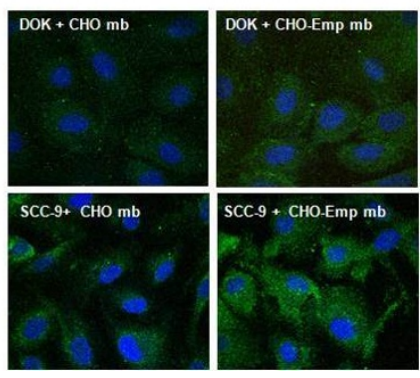

B

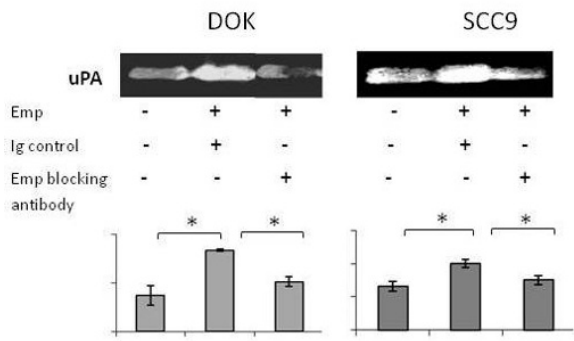

C

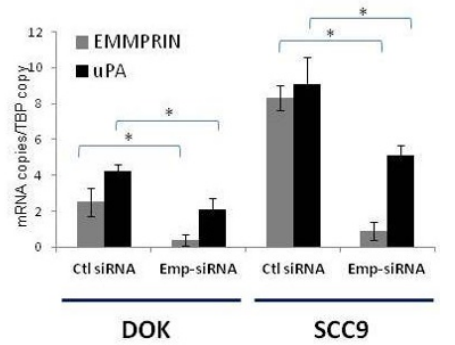

Figure 3 EMMPRIN regulates uPA in oral dysplastic DOK and tumor SCC-9 cell lines. A, (a) CHO cells were transfected with EMMPRIN CDNA as previously described [18]. Membranes were isolated from CHO-Emp and CHO control cells (CHO-Emp Mb and CHO Mb, respectively) by differential centrifugation and $10 \mu \mathrm{g}$ of membrane extract were analyzed for EMMPRIN content by immunoblotting. (b) DOK and SCC-9 cells (80\% confluence) were incubated with $20 \mathrm{\mu g} / \mathrm{mL}$ CHO Mb or CHO-Emp Mb in serum-free medium for $24 \mathrm{~h}$ and the conditioned medium was analyzed for uPA activity using casein-plasminogen zymography and for gelatinase activities of MMP-2 and MMP-9 using gelatin zymography (one representative zymography of three independent experiments). (c) EMMPRIN, UPA, MMP-2, MMP-9 and TIMP-1 transcripts were quantified using quantitative RT-PCR in DOK and SCC-9 cells incubated for $24 \mathrm{~h}$ with CHO Mb or CHO-Emp Mb $(20 \mu \mathrm{g} / \mathrm{mL})$. Columns are means of gene expression relative to TBP housekeeping gene of at least three independent experiments carried out in triplicate; bars, SD. * denotes significant difference with $\boldsymbol{p}<\mathbf{0 . 0 5}$. (d) SCC-9 and DOK cells were grown in microscope slide chambers to 50-60\% confluence and incubated with $\mathrm{CHO}$ Mb or CHO-Emp Mb $(20 \mathrm{\mu g} / \mathrm{mL})$. After $24 \mathrm{~h}$, cells were immunostained for uPA using a goat anti-human antibody (green) and counterstained with DAPI (blue). A more intense staining was observed in CHO-Emp mb treated DOK and SCC-9 cells compared to the control CHO mb treated cells. B, SCC-9 and DOK cells were incubated with $20 \mu \mathrm{g} / \mathrm{mL}$ of an anti-EMMPRIN blocking antibody (Ancell, Bayport, MN) or with a non-immune lgG antibody in serum-free medium. After $24 \mathrm{~h}$ incubation, conditioned medium was harvested for gelatinase and uPA casein zymography. Columns represent average values of the densitometric quantification from at least three independent experiments carried out in triplicate; bars, SD. * denotes significant difference with $p<0.05$. C, DOK and SCC-9 cells were transfected with EMMPRIN siRNA (EmpsiRNA) or scrambled control siRNA (CtI siRNA) at $33 \mathrm{nmol} / \mathrm{L}$ concentration. EMMPRIN and UPA mRNA expression was evaluated by quantitative RT-PCR analyses. Columns represent mean \pm SD of relative expression to TBP housekeeping gene of at least 3 independent experiments carried out in triplicate; bars, SD. ${ }^{*}$ denotes significant difference with $p<0.05$.

stimulate the serine uPA proteinase system in breast cancer, thus representing an additional degradation pathway enhancing its tumor invasion potential [18]. Our results showing that EMMPRIN also regulated uPA in oral tumors and colocalized with it in the tumoral tissues where both EMMPRIN and UPA were overexpressed suggest that this pathway may play an important role in oral tumor progression. In addition, amiloride, a uPA inhibitor significantly reduced invasion of two oral tumoral cell lines used in this study, 
A

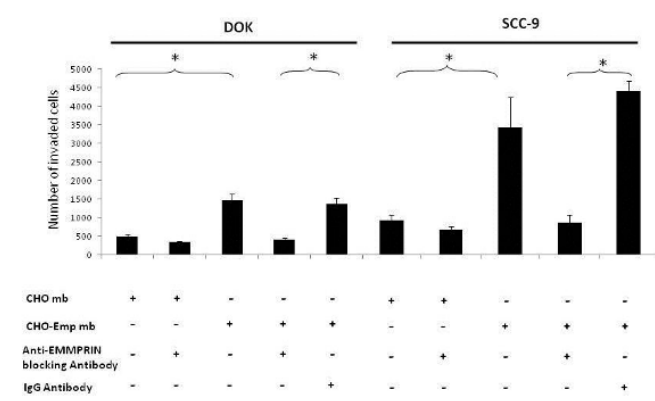

B

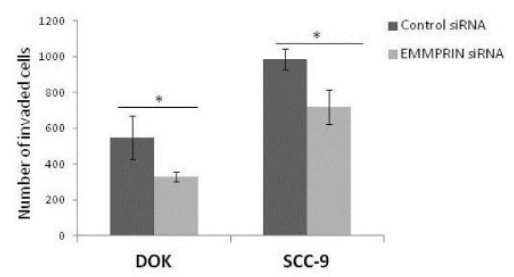

C

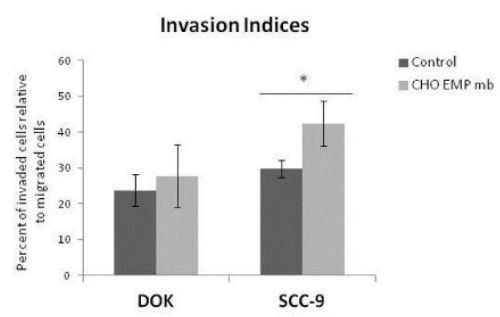

D
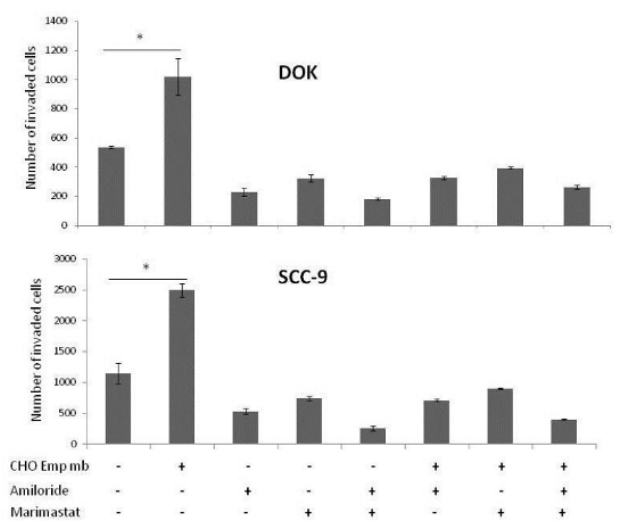

Figure 4 EMMPRIN regulates invasion in oral dysplastic DOK and tumor SCC-9 cell lines in an MMP and uPA dependent manner. A, The in vitro invasive property of DOK and SCC-9 cells incubated with CHO-Emp membranes and treated or not with an anti-EMMPRIN blocking antibody (20 $\mu \mathrm{g} / \mathrm{mL}$ ) were compared using tissue culture Transwell inserts (8-mm pore size; BD Biosciences) placed in a 24-well culture plate. Cells incubated with $\mathrm{CHO}$ control or treated with an anti-lgG antibody were used as control. Cells $\left(1 \times 10^{5}\right)$ suspended in serum-free media were seeded into the upper well of each insert onto membranes coated with growth factor-reduced Matrigel (BD Biosciences). After $48 \mathrm{~h}$ incubation, cells that remained in the top compartment were removed by cotton swabs, and cells on the underside of insert filters were fixed, stained, and counted under a microscope. The columns shown represent average values from at least three independent experiments carried out in triplicate; bars, SD. ${ }^{*}$ denotes significant difference with $p<0.05$. B, DOK and SCC-9 cells were transfected with EMMPRIN siRNA or scrambled siRNA (CtI siRNA) prior to invasion assays. The columns represent means of three independent experiments carried out in triplicate; bars, SD. C, Invasive Indices. DOK and SCC-9 cells $\left(1 \times 10^{5}\right)$ seeded into the upper well of tissue culture Transwell inserts coated with growth factor-reduced Matrigel (for invasion assay) or not coated (for migration assay) were incubated with $\mathrm{CHO}$ or $\mathrm{CHO}-\mathrm{Emp}$ membranes (Control and $\mathrm{CHO}$ Emp mb respectively). After $48 \mathrm{~h}$ of incubation, migrating or invading cells on the underside of insert filters were fixed, stained, and counted under a microscope. Invasion Indices were calculated as percent of the invaded cells relative to the migrated cells. The columns shown represent average values from at least three independent experiments carried out in triplicate; bars, SD. * denotes significant difference with $p<0.05$. D, Relative contribution of UPA and MMPs to the in vitro invasive property of DOK and SCC-9 cells. Cells $\left(1 \times 10^{5}\right)$ were seeded into the upper well of matrigel coated inserts and incubated with CHO or CHO-Emp membranes. UPA inhibitor amiloride $(20 \mathrm{nmol} / \mathrm{L})$ or MMP inhibitor marimastat $(10 \mu \mathrm{mol} / \mathrm{L})$ were added alone or in combination together with the membranes. After 48 $\mathrm{h}$ invading cells were fixed, stained, and counted. Columns represent average values from at least three independent experiments carried out in triplicate; bars, SD. * denotes significant difference with $p<0.05$. 
DOK and SCC-9, representing the dysplastic and the invasive stages respectively. The fact that combining amiloride with marimastat, an MMPs inhibitor, caused a greater inhibition of EMMPRIN-mediated invasion than either of these inhibitors alone suggests that both pathways function in parallel and underscores EMMPRIN's ability to regulate invasion through both uPA and MMPs. EMMPRIN was shown to be without effect on the MMP inhibitors TIMPs so the induction of MMPs is likely to cause a direct increase in proteolysis [28]. Whether the increase in UPA by EMMPRIN in OSCC is accompanied by a parallel regulation of its inhibitor PAI1 remains to be determined, but the inhibition by amiloride of the increased invasion following EMMPRIN treatment suggests a net increase in the active UPA.

The MAP kinase P38 was implicated in the regulation of UPA, certain MMPs and EMMPRIN itself and may represent a common mechanism for their regulation [7]. As EMMPRIN was suggested to serve as its own receptor in neighbouring cells, it is possible that constitutive EMMPRIN acts as a receptor to the exogenous membrane bound EMMPRIN, initiating signalling pathways that result in P38 activation.

Silencing EMMPRIN in head and neck squamous carcinoma (HNSCC) cells was shown to result in significant suppression of tumor growth [32]. Furthermore, a correlation between the invasive activity and the transcriptional activation of the $u P A$ gene has already been reported in oral tumors and cultured OSCC cells and tumors with high levels of both uPA and UPAR were shown to be more invasive $[20,33,34]$. Correspondingly, our results demonstrate that the more invasive OSCC express more EMMPRIN and more uPA than the dysplastic oral tissues. This was also observed when comparing the corresponding cell lines. This suggests that EMMPRIN levels determine the invasive potential through the regulation of the two proteolytic systems, MMPs and uPA; the increase in EMMPRIN expression during progression upregulates protease production and promotes greater invasion. Indeed, when the less invasive DOK cells were treated with exogenous EMMPRIN, their invasiveness approached that of the SCC9 invasive cells.

\section{Conclusions}

Although the role of EMMPRIN in tumor growth and metastasis has been studied in detail, the mechanisms by which it exerts its effects in OSCC tumorogenesis are not completely understood. Our results showing the induction of the uPA system provide important insights into the mechanism by which EMMPRIN contributes to oral tumor cell invasion and progression.

\section{Acknowledgements}

Grant support: Fondation pour la recherche médicale (FRM) (G. Lescaille), and PPF funding from Ministère de la Recherche and Conseil Régional IleDe-France (confocal microscopy imaging). We thank Pr E Tartour for providing the cells and helpfull discussions and Dr Niclas Satterblad and Guy Millot for technical support.

\section{Author details}

${ }^{1}$ Inserm, UMR-S 940, Paris F-75010, France. ${ }^{2}$ CNRS, EAC 7149, Laboratoire CRRET, Université 12, Créteil F-94000, France. ${ }^{3}$ Cabinet de Dermatopathologie 35, avenue Mathurin Moreau, 75019 Paris, France. ${ }^{4}$ AP-HP, Hôpital SaintLouis, Laboratory of Pharmacology, Paris F-75010, France. ${ }^{5}$ Université Paris 12, Créteil, Paris, France. ${ }^{6}$ Université Paris 7- IUH, Paris F-75010, France. ${ }^{7}$ Département de Dermatologie, hôpital Saint Louis, Paris F-75010, France. ${ }^{8}$ Laboratoire de Pharmacologie and INSERM U940, Hôpital Saint-Louis, 27, rue Juliette Dodu, 75010 Paris, France.

\section{Authors' contributions}

GL: carried out in vitro experiments; SM (S Menashi): participated in the design of the study, data analyses and writing of the manuscript; $\mathbf{B C B}$ : coordinated tissue specimens study and analyzed Immunohistochemistry data; FK: carried out experiments; CQ: carried out experiments; MPP: carried out qPCR analyses; BN: developed analytical tools; FC: participated in the design of the study and research discussions; $\mathbf{C L}$ : participated in the design of the study and data analyses; SM (S Mourah): participated in the design of the study, statistical and data analysis and writing of the manuscript. All authors read and approved the finalmanuscript.

\section{Conflict of interests}

The authors declare that they have no competing interests.

Received: 9 August 2011 Accepted: 23 March 2012

Published: 23 March 2012

\section{References}

1. Prince A, Aguirre-Ghizo J, Genden E, Posner M, Sikora A: Head and neck squamous cell carcinoma: new translational therapies. Mt Sinai J Med 2010, 77(6):684-699.

2. Specenier $P$, Vermorken JB: Advances in the systemic treatment of head and neck cancers. Curr Opin Oncol 2010, 22(3):200-205.

3. Braakhuis BJ, Snijders PJ, Keune WJ, Meijer CJ, Ruijter-Schippers HJ, Leemans CR, Brakenhoff RH: Genetic patterns in head and neck cancers that contain or lack transcriptionally active human papillomavirus. J Natl Cancer Inst 2004, 96(13):998-1006.

4. Shi Z, Stack MS: Urinary-type plasminogen activator (UPA) and its receptor (UPAR) in squamous cell carcinoma of the oral cavity. Biochem J 2007, 407(2):153-159.

5. Siqueira AS, Gama-de-Souza LN, Arnaud MV, Pinheiro JJ, Jaeger RG: Laminin-derived peptide AG73 regulates migration, invasion, and protease activity of human oral squamous cell carcinoma cells through syndecan-1 and beta1 integrin. Tumour Biol 2010, 31(1):46-58.

6. Biswas C, Zhang Y, DeCastro R, Guo H, Nakamura T, Kataoka H, Nabeshima K: The human tumor cell-derived collagenase stimulatory factor (renamed EMMPRIN) is a member of the immunoglobulin superfamily. Cancer Res 1995, 55(2):434-439.

7. Huet E, Gabison EE, Mourah S, Menashi S: Role of emmprin/CD147 in tissue remodeling. Connect Tissue Res 2008, 49(3):175-179.

8. Muramatsu T, Miyauchi T: Basigin (CD147): a multifunctional transmembrane protein involved in reproduction, neural function, inflammation and tumor invasion. Histol Histopathol 2003, 18(3):981-987.

9. Nabeshima K, Iwasaki H, Koga K, Hojo H, Suzumiya J, Kikuchi M: Emmprin (basigin/CD147): matrix metalloproteinase modulator and multifunctional cell recognition molecule that plays a critical role in cancer progression. Pathol Int 2006, 56(7):359-367.

10. Yan L, Zucker $S$, Toole BP: Roles of the multifunctional glycoprotein, emmprin (basigin; CD147), in tumour progression. Thromb Haemost 2005, 93(2):199-204.

11. Chen X, Lin J, Kanekura T, Su J, Lin W, Xie H, Wu Y, Li J, Chen M, Chang J: A small interfering CD147-targeting RNA inhibited the proliferation, invasiveness, and metastatic activity of malignant melanoma. Cancer Res 2006, 66(23):11323-11330. 
12. Kanekura T, Chen X, Kanzaki T: Basigin (CD147) is expressed on melanoma cells and induces tumor cell invasion by stimulating production of matrix metalloproteinases by fibroblasts. Int J Cancer 2002, 99(4):520-528.

13. Toole BP, Slomiany MG: Hyaluronan, CD44 and Emmprin: partners in cancer cell chemoresistance. Drug Resist Updat 2008, 11(3):110-121.

14. Bougatef F, Quemener C, Kellouche S, Naimi B, Podgorniak MP, Millot G, Gabison EE, Calvo F, Dosquet C, Lebbe C, et al: EMMPRIN promotes angiogenesis through hypoxia-inducible factor-2alpha-mediated regulation of soluble VEGF isoforms and their receptor VEGFR-2. Blood 2009, 114(27):5547-5556.

15. Lacal PM, Ruffini F, Pagani E, D'Atri S: An autocrine loop directed by the vascular endothelial growth factor promotes invasiveness of human melanoma cells. Int J Oncol 2005, 27(6):1625-1632.

16. Tang Y, Nakada MT, Kesavan P, McCabe F, Millar H, Rafferty P, Bugelski P, Yan L: Extracellular matrix metalloproteinase inducer stimulates tumor angiogenesis by elevating vascular endothelial cell growth factor and matrix metalloproteinases. Cancer Res 2005, 65(8):3193-3199.

17. Bougatef F, Menashi S, Khayati F, Naimi B, Porcher R, Podgorniak MP, Millot G, Janin A, Calvo F, Lebbe C, et al: EMMPRIN promotes melanoma cells malignant properties through a HIF-2alpha mediated up-regulation of VEGF-receptor-2. PLoS One 2010, 5(8):e12265.

18. Quemener C, Gabison EE, Naimi B, Lescaille G, Bougatef F, Podgorniak MP, Labarchede G, Lebbe C, Calvo F, Menashi S, et al: Extracellular matrix metalloproteinase inducer up-regulates the urokinase-type plasminogen activator system promoting tumor cell invasion. Cancer Res 2007, 67(1):9-15.

19. Zucker S, Hymowitz M, Rollo EE, Mann R, Conner CE, Cao J, Foda HD, Tompkins DC, Toole BP: Tumorigenic potential of extracellular matrix metalloproteinase inducer. Am J Pathol 2001, 158(6):1921-1928.

20. Nagata M, Fujita H, Ida H, Hoshina H, Inoue T, Seki Y, Ohnishi M, Ohyama T, Shingaki S, Kaji M, et al: Identification of potential biomarkers of lymph node metastasis in oral squamous cell carcinoma by cDNA microarray analysis. Int J Cancer 2003, 106(5):683-689.

21. Ziober AF, Falls EM, Ziober BL: The extracellular matrix in oral squamous cell carcinoma: friend or foe? Head Neck 2006, 28(8):740-749.

22. Lindberg P, Larsson A, Nielsen BS: Expression of plasminogen activator inhibitor-1, urokinase receptor and laminin gamma-2 chain is an early coordinated event in incipient oral squamous cell carcinoma. Int $J$ Cancer 2006, 118(12):2948-2956.

23. Rosenthal EL, Shreenivas S, Peters GE, Grizzle WE, Desmond R, Gladson CL: Expression of extracellular matrix metalloprotease inducer in laryngeal squamous cell carcinoma. Laryngoscope 2003, 113(8):1406-1410.

24. Vigneswaran N, Beckers S, Waigel S, Mensah J, Wu J, Mo J, Fleisher KE, Bouquot J, Sacks PG, Zacharias W: Increased EMMPRIN (CD 147) expression during oral carcinogenesis. Exp Mol Pathol 2006, 80(2):147-159.

25. Bordador LC, Li X, Toole B, Chen B, Regezi J, Zardi L, Hu Y, Ramos DM: Expression of emmprin by oral squamous cell carcinoma. Int J Cancer 2000, 85(3):347-352.

26. Dang D, Atakilit A, Ramos DM: EMMPRIN modulates migration and deposition of TN-C in oral squamous carcinoma. Anticancer Res 2008, 28(4B):2049-2054.

27. Chang SE, Foster S, Betts D, Marnock WE: DOK, a cell line established from human dysplastic oral mucosa, shows a partially transformed nonmalignant phenotype. Int J Cancer 1992, 52(6):896-902.

28. Toole BP: Emmprin (CD147), a cell surface regulator of matrix metalloproteinase production and function. Curr Top Dev Biol 2003, 54:371-389.

29. Gabison EE, Hoang-Xuan T, Mauviel A, Menashi S: EMMPRIN/CD147, an MMP modulator in cancer, development and tissue repair. Biochimie 2005, 87(3-4):361-368.

30. Liu Z, Hartman YE, Warram JM, Knowles JA, Sweeny L, Zhou T, Rosenthal EL: Fibroblast growth factor receptor mediates fibroblastdependent growth in EMMPRIN-depleted head and neck cancer tumor cells. Mol Cancer Res 2011, 9(8):1008-1017.

31. Kanekura $T$, Chen X: CD147/basigin promotes progression of malignant melanoma and other cancers. J Dermato/ Sci 2010, 57(3):149-154.

32. Newman JR, Bohannon IA, Zhang W, Skipper JB, Grizzle WE, Rosenthal EL: Modulation of tumor cell growth in vivo by extracellular matrix metalloprotease inducer. Arch Otolaryngol Head Neck Surg 2008, 134(11):1218-1224
33. Ghosh S, Koblinski J, Johnson J, Liu Y, Ericsson A, Davis JW, Shi Z, Ravosa MJ, Crawford S, Frazier S, et al: Urinary-type plasminogen activator receptor/alpha 3 beta 1 integrin signaling, altered gene expression, and oral tumor progression. Mol Cancer Res 2010, 8(2):145-158.

34. Ghosh S, Munshi HG, Sen R, Linz-McGillem LA, Goldman RD, Lorch J, Green KJ, Jones JC, Stack MS: Loss of adhesion-regulated proteinase production is correlated with invasive activity in oral squamous cell carcinoma. Cancer 2002, 95(12):2524-2533.

\section{Pre-publication history}

The pre-publication history for this paper can be accessed here: http://www.biomedcentral.com/1471-2407/12/115/prepub

doi:10.1186/1471-2407-12-115

Cite this article as: Lescaille et al:: EMMPRIN/CD147 up-regulates urokinase-type plasminogen activator: implications in oral tumor progression. BMC Cancer 2012 12:115.

\section{Submit your next manuscript to BioMed Central and take full advantage of:}

- Convenient online submission

- Thorough peer review

- No space constraints or color figure charges

- Immediate publication on acceptance

- Inclusion in PubMed, CAS, Scopus and Google Scholar

- Research which is freely available for redistribution

Submit your manuscript at www.biomedcentral.com/submit 